\title{
eKISS: Sharing Experiences in Families Through a Picture Blog
}

\author{
Thomas Dalsgaard, Mikael B. Skov, Bo Ramsdahl Thomassen \\ Department of Computer Science, Aalborg University \\ Selma Lagerløfsvej 300, DK-9220 Aalborg East, Denmark
}

\{thomasd, dubois, bo\}@cs.aau.dk

\begin{abstract}
Contemporary family life can be very stressful and many families are often busy and separated by time or distance. Physical separation makes it difficult to maintain an awareness of each other and the feeling of intimacy. But lack of such intimacy can result in insecure and troubled children. This paper outlines eKISS, a picture weblog for mediating intimacy between children and parents. eKISS supports asynchronous sharing of experiences from the children to their parents while being physically separated. Communication is based on pictures and text sent through mobile technology and shared on a weblog available to the family. A longitudinal field evaluation revealed that eKISS was able to support acts of intimacy by providing insight, new communication channel, and the possibility to easily share experiences. It also revealed that eKISS was most useful when the family was separated for longer periods of time.
\end{abstract}

\section{Categories and Subject Descriptors}

H.5.2 [Information Interfaces and Presentation (e.g., HCI)]: Group and Organisation Interfaces - computer-supported cooperative work.

\section{General Terms}

Design, Human Factors.

\section{Keywords}

Children, parents, intimacy, mediated intimacy, picture sharing, blog.

\section{INTRODUCTION}

Contemporary family life can be very stressful and many families are often busy and separated by time or distance. Jacobsen and Tonboe found that the time families spent together nursing family relations has decreased significantly during the last decades [8]. Growing workloads of parents and the fact that children spend much time outside the home imply a decreased awareness of other family members. Domestic problems in families such as couple separation or divorce only make distributed family life even more difficult.

(c) Thomas Dalsgaard, Mikael B. Skov, Bo Ramsdahl Thomassen, 2007 Published by the British Computer Society

People and Computers XXI-HCI... but not as we know it: Proceedings of HCI 2007

Linden J. Ball, M. Angela Sasse, Corina Sas, Thomas C. Ormerod, Alan Dix, Peter Bagnall, and Tom McEwan (Editors)
Psychologists argue that for children to be able to feel safe and loved, they need attention, intimacy and care in their upbringing. Lack of intimacy will often result in insecure and troubled children [15]. Therefore, intimacy plays an important part in any relationship between children and their parents. In the light of this need and the decreasing time parents spend with their children, the families need to find new ways of interacting in order to gain the same insight in each other's life, and thereby maintain the intimate relations they need. As an example, many parents arrange for the whole family to eat together at least once a day [4]. At this meal, they try to eliminate disturbing elements like the TV, and thereby provide settings, which yields communication, intimacy and presence.

Zuckerman and Maes claim that geographical separation of many families makes it difficult to maintain an awareness of each other and the feeling of intimacy [18]. Furthermore, in several societies children and grandparents are not co-habiting, making it difficult for them to maintain social connections. Such connections have shown to improve the wellness of aged people helping them to remain living in their own homes, thus reducing the cost to the residential care system. Intergenerational social connections between children, their parents, and grandparents are vital for the well-being of all family members, but distributed family life poses a number of substantial challenges that affect both society and individuals. We are currently witnessing information and communication technologies being used to maintain social connections with family members to achieve better awareness of each other and thereby create a feeling of intimacy. For example, technologies like mobile phones, E-mail, instant messaging and SMS have been adapted to help us feel connected with people that we care about [16]. While such technologies were designed to support activities in work domains, a strong desire of establishing and maintaining social relations have pulled such technologies from the work domain into the domestic domain and shaped them for a social use. Emerging information and communication technologies are about to change and affect how we interact and coordinate with each other and thereby they mediate awareness [16]. This paper reports from the design of mobile picture blog system for promoting and supporting intimacy. We call this system eKISS. The design of eKISS was inspired by themes identified in child-parent intimacy.

\section{RELATED WORK}

Family life and intimate social relations receive increasingly more attention and focus within human-computer interaction and interaction design [9]. However, the unique and special intimate relationship between children and their parents needs further investigations and studies. Contemporary research on mediated intimacy primarily focuses on adults, friends, and lovers or on systems supporting such relations. 
Various research studies suggest different approaches and strategies for mediating intimacy and thus enhance the feeling of presence. Siio et al. present Peek-a-Drawer, a system for enhancing the feeling of presence between children and their grandparents by exchanging artifacts [14]. Whatever the child puts in the top drawer is displayed in the bottom drawer at the grandparents and visa versa. O'Hara et al. outline a system that makes it possible to send text messages to the family homes and not to a specific person [12]. Thereby they attempt to enhance the sense or feeling of unity in families as all household members can share the messages.

In HCI research, much work attempts to understand how to enhance the feeling of presence through technology use. Counts and Fellheimer investigate the use of pictures to enhance the sense of social presence [2]. Through their experimental photosharing system, they found that easy and simple picture sharing between family and friends resulted in users having more fun, sharing more photos, and having an enhanced sense of social presence. Markopoulos et al. use pictures to enhance the feeling of presence. They design a system where the entire family can share their day apart by sending pictures to a system placed in the home [10].

Systems for supporting mediated intimacy are not designed exclusively for use while being separated. Some systems are intended to be used while being together in the home. Stevens et al. design a system called the 'living Memory Box' [11]. The purpose of the system is to enhance the use and organization of family memories. Hindus et al. designs several prototypes. One of them is 'Room Link', which places a microphone and a speaker in each room in the home. Thereby the participants are always able to here what is going on in the other rooms [7]. The idea of the system is to enhance the feeling of presence between two people sitting in different rooms.

Hoefnagels et al. focus on how to reduce friction in scheduling and coordinating lives of families [6]. Their focus is on the practical coordination, but to understand these aspects they also take the social relations and intimacy of families into account. Battarbee et al. have a primary focus on mediating intimacy, but they do not place their focus directly on the family. Instead, they come up with design ideas for mediating intimacy across cities [1]. The users of their systems could be children, adults, families, friends etc.

\section{THE eKISS BLOG}

We designed eKISS to support parents and children in their intimate communication, and we base this design on a previous study of child-parent intimacy [4]. The system name represents an electronic kiss as we see the kiss as a basic symbol of intimacy. eKISS is also short for 'electronic Knowledge and Intimacy Support System'.

\subsection{Mediated Intimacy Children and Parents}

In order to design eKISS, we conducted an empirical study to understand the way children and parents share and mediate intimacy. The study involved three families with children. We deployed a cultural probe within the families and asked them to use it for a seven-week period. In this period, they were instructed to use the probe to document their family communication and intimacy. We used contextual interviews to clarify the data collected through the cultural probe. The following section describes some of the findings from the study, which we have used as a foundation for eKISS. More details on the empirical study can be found in O'Hara et al. [12].
Our main results led to a thematic scheme of children-parents intimacy providing an overview of key themes. Grounded in characteristics of the family structure, we found intimacy themes evident in the child-parent relation, which were not a normal part of strong-tie relations. We also found intimacy themes defining the strong-tie relations, which did not seem to play a specific role in child-parent interaction. One of the differences we found between the two types of relations was that the relationship between a child and its parents is unequal. On one hand, the parents want to gain knowledge of the child's life and they feel a responsibility to provide the child with intimacy and support. Thereby they hope they can give the child a good upbringing and at the same time make him or her feel the warmth and safety of the family bonds. On the other hand, the children may want these things, but they do not feel much responsibility towards maintaining the relationship. As an example of this, the parents told that it was difficult for them to gain insight in the children's day away from the parents. The children were not 'chatty' on this area. This lack of reciprocity from the children seems to be the main source of differences between strong-tie relationships and child-parents relationships.

\subsection{Identified Challenges}

From the results of our empirical study, we identified the following three challenges when mediating intimacy between children and their parents:

1. The parents found it difficult to achieve a continuing insight in the lives and wellbeing of their children while being separated.

2. When united after separation, the parents had problems understanding and relating to the experiences the children have had while being apart.

3. The children found it difficult to describe or retell the experiences they have had while being separated from their parents.

The first challenge reflects the parents' effort to keep in contact with their children while separated. The parents tried to gain a continuing insight in the lives and wellbeing of their children, as a part of their parental facilitation of care and support. The parents wanted assurance and they wanted to be able to support their children if anything was wrong. But parents found it difficult to achieve this insight as the children often neglected to disclose information to the parents. They either forgot or they found other things more interesting.

The second challenge exemplifies parents asking their children what they had been doing during the day or what they had experienced. The parents often had few references from the child's day and they would ask questions like "what have you been up to today?" It was often hard for the children to process a whole day of experiences. Therefore, they just told about the few things they found interesting to share or they simply replied that they could not remember what they had been doing.

The third challenge illustrates the fact that the children found it difficult or impossible to retell all experiences they have had. The children expressed that they often had difficulties remembering what they had experienced during the day, or they simply did not bother to tell it. Often the children were not motivated to tell about their experiences, as other things were more interesting.

The above-identified challenges informed the design and implementation of mobile prototype system for mediating social awareness and intimacy. 


\subsection{System Functionality and Architecture}

We designed eKISS as a mobile picture blog. The system consists of a website that handles pictures and texts sent from the children to eKISS by sorting them according to the date and time they are sent and presenting them to the users in a structured way. Every family has their own personal weblog only accessible by members of the family.

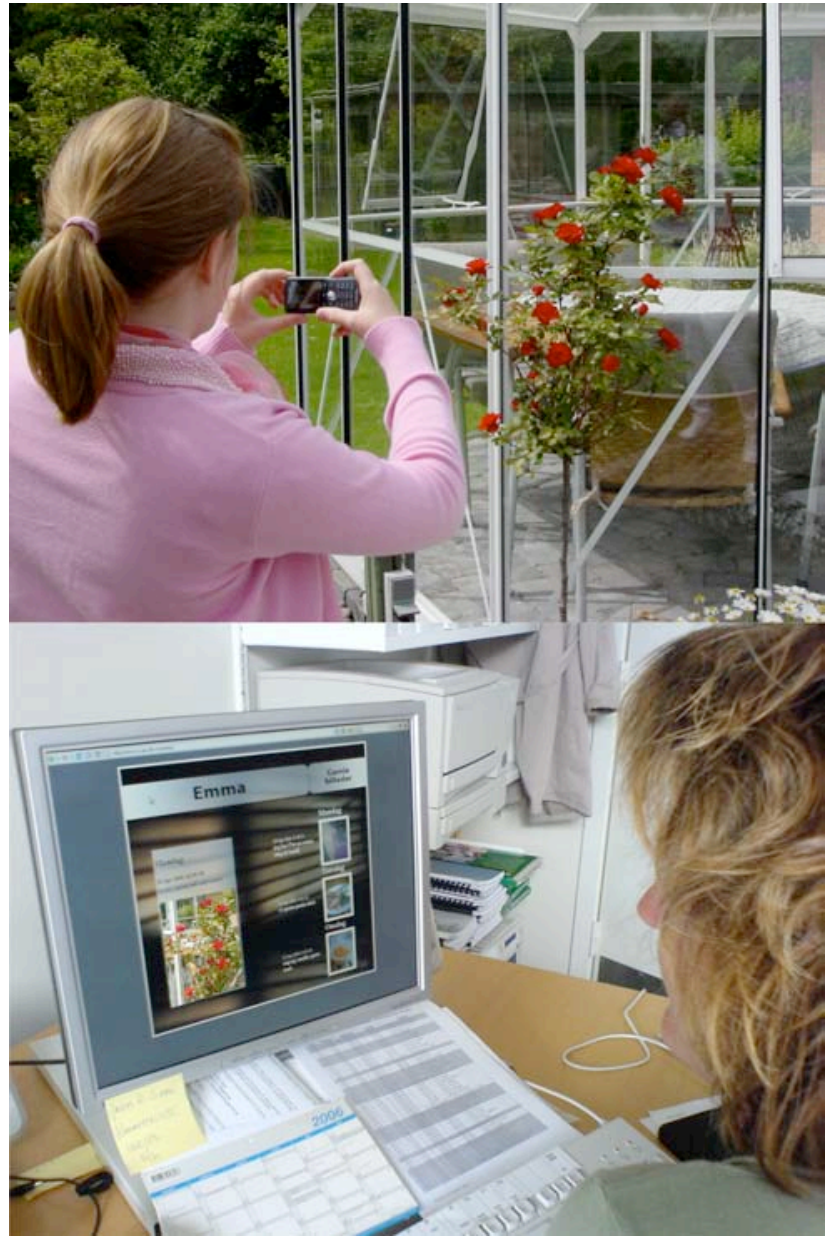

Figure 1. Sharing of pictures through eKISS.

eKISS is fed with pictures from the children who use their regular camera phones to take pictures of objects, people and situations they wish to share with their parents (see Figure 1). The children can also add text comments to the pictures if they want to. The pictures are then sent from the phone as an MMS (Multimedia Messaging Service). The phone needs no special software installed to be able to send the pictures. The only requirement is that the phone needs to support GPRS (General Packet Radio Service), which is a common transfer technology used for mobile services. A graphic overview of how eKISS works can be seen in Figure 2.

Messages are automatically shown on a blog (moblog.tv2.dk). We chose to use an existing weblog, as we did not have the technology to extract pictures from an MMS-message and place them on the Internet. TV2's Moblog provides an RSS feed which present the latest pictures and the added text. We used this RSS feeds to extract the pictures to eKISS. Every 5 minutes eKISS checks the RSS feed to see if any new images has been posted. If new pictures occur, they are added to eKISS along with the text, date, and time.

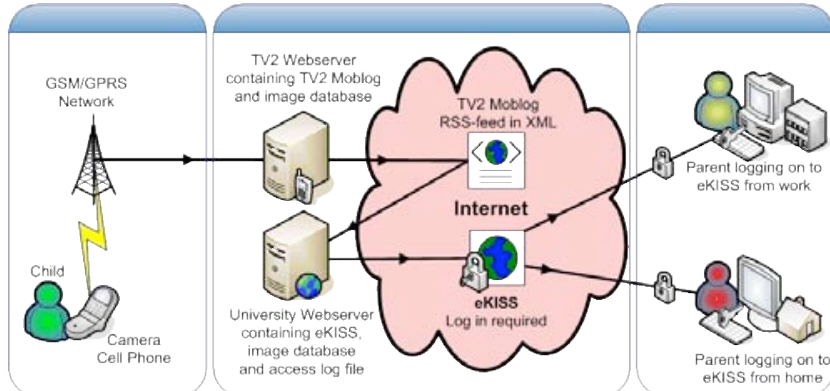

Figure 2. Information flow in eKISS.

We used the XSLT (Extensible Style Sheet Language Transformations) in three steps [17]. The first step copies and arranges the parts of the original xml-file that is needed to show the desired content on the website. The second step rearranges the content in a way that is easier to use directly when building the website in the later steps. The third step uses the resulting xml-file to build the website containing the most resent pictures.

The user interface in eKISS displays the pictures and text that has been sent. The parents can access the webpage from any computer with access to the Internet and a browser installed. When entering the webpage's address, the browser prompts the parent for username and password. After they have logged in, they are prompted with the front page of the weblog. The page displays the four newest pictures sent to the system along with date and time they are sent. The newest picture is displayed in large, while the rest is smaller.

If the parents click on one of the small pictures, a popup window will display the picture in its original size. The text saying 'Gamle billeder' (top right in Figure 3) is a link to a second page which displays all previously sent pictures in chronologic order (illustrated in Figure 4). An example cut of this page is shown below.

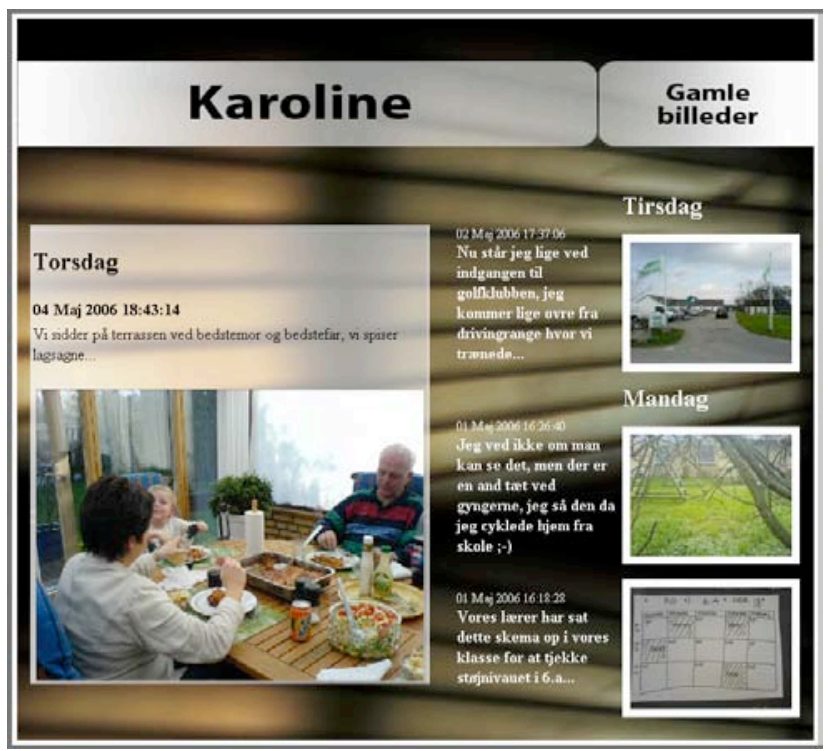

Figure 3. Front page in eKISS.

\section{DESIGN ARGUMENTATION}

In the design phase we used the results from our empirical study on parent/child intimacy combined with the experiences and results that papers from the leading conferences and journals in this research area has presented [3, 4]. We used these data to design a system that allowed the support of 
intimacy between children and parents and at the same time would take the three challenges above into consideration.

In the following section we more thoroughly outline how eKISS was designed and how we have conceptualized the challenges into more specific design criteria. Finally, we used themes of child/parent intimacy as identified in [4].

\subsection{Self-Disclosure}

Self-disclosure is the revelation and willingness to open one self to the other. To facilitate that children self-disclose, eKISS provides simple and straightforward use. If the child should use an extensive amount of time on the system, we thought that it could become a burden to them. eKISS utilizes MMS technology. We knew that many children were aware that it was possible to send pictures from the phone, but also that it was expensive and therefore they didn't use it very much. We wanted to encourage the children to use eKISS by giving them the possibility to try the MMS technology.

The design of eKISS yields for the parents to ask the children about the pictures they have taken. This provides the children with attention from their parent, and this attention can function as a motivator for the children. To make self-disclosure possible when the children wanted it, and not only when the parents needed information, we made the communication asynchronous. This was done by storing information sent to eKISS and making it always available and accessible. In this way, the parents would be able to access the information when they have the time and need. It will also be possible to recall the information and use it again in different contexts. This also means that the interaction patterns will both be less intrusive in the daily routines of work and leisure and accommodate the unstructured and non-routine behaviour of children.

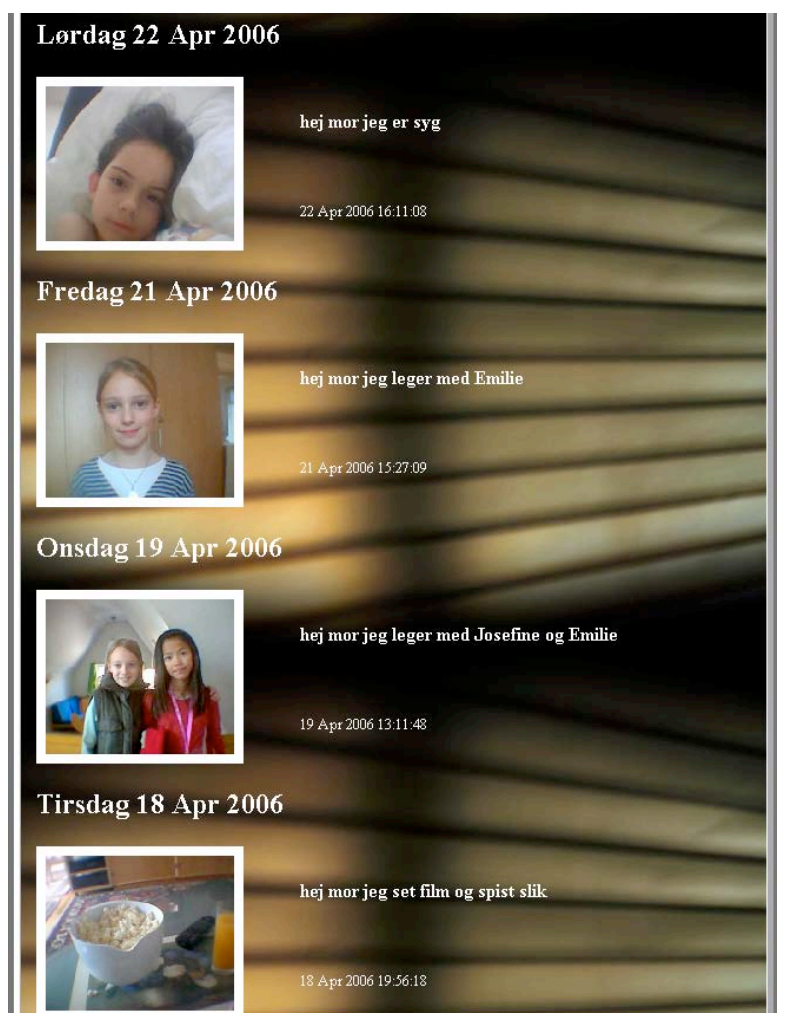

Figure 4. Segment of the list of old pictures in eKISS.

eKISS provides the parent with 'snap-shots' of the child's experiences through pictures. This makes it easier for them to empathize with the child and understand what he or she has been up to. For instance a picture from a place the child has been, makes it easier for the parents to understand what the child is explaining when they talk about things they have been doing in this specific place. In summary, eKISS provides the child and the parents with a base that makes them able to understand and discuss the experiences they have had while being apart by making the children share pictures of their experiences. This can create a shared past for the family and make it easier for the parents to empathize with the child when he or she is sharing an experience.

eKISS is intended to enhance the children's receptiveness towards communicating with the parents in more ways. First, the children are instructed to take pictures of things they wish to share with the parents. Thereby, it becomes more exiting for the children to explain what the pictures show while at the same time, the pictures provide a reference for future conversations. The pictures should also make it easier for the child to recall and relate to experiences and situations.

eKISS provides no direct means for two-way interaction (or communication) between the child and the parents as we wanted to avoid actual conversations while separated. Instead, we hoped that the lack of feedback possibilities would trigger or initiate conversations between the children and parents when together. However, we were aware that this lack of feedback could challenge the children's (and possibly) the parents' perception and attitudes towards the system. Secondly, when the parents use the pictures in their communication with the child, the child might realize that, if they take pictures, they gain attention from their parents. As children often wants and needs attention from their parents this will function as a motivator for the child to take pictures and thereby share more experiences.

In summary, eKISS makes it easier for the child to retell experiences by providing them with a technology that they can use for encapsulating the experiences they wish to share, and by motivating them to share pictures by providing them with attention from the parents.

\subsection{Unity}

Unity is the sense of affiliation to a group with shared interests. It is the feeling of belonging to something that is more important than oneself. eKISS facilitates and encourages the unity of the family by supporting one-to-many interactions. This means the interaction is not constrained to one child and one parent. eKISS enables the child to send a message to the entire family, and both parents thereby get the same information. By making it possible for the child to send the information to both parents on the same time, eKISS encourages the child to keep both parents in mind and provide them both with information, and thereby it supports the unity.

Normally the unequal relations between children and their parents and the lack of reciprocity in these relations place the maintenance of family bonds and unity solely with the parents. By encouraging the children to uphold and maintain these bonds, eKISS thereby places some of the workload of strengthening the bonds on the children.

In summary, we designed for children to be able to show elements from their lives through pictures and text in MMS messages. The pictures are stored and made accessible for the whole family at any given time, provided they have access to eKISS. By giving both parents access to the information from the child, eKISS thereby supports the unity of the family. 


\subsection{Commitment}

Commitment defines the on-going process of a relationship and it is the joint feeling of being on a shared journey or having a shared past. eKISS supports enhancement of the shared past between children and their parents by letting the children take pictures of the things they wish to share with their parents. Thereby the children do not have to remember to tell the parents, as the parents already have received a picture with describing text. eKISS is designed to allow the family to access it from their home. This way the parents can recall the pictures while being with the child, and thereby they can easily ask the child about a specific experience and gain the shared past.

\subsection{Expressive}

Expressive acts of intimacy often include non-verbal interaction and often ambiguous exchanges. eKISS addresses children's interchanging needs and desires for intimate acts. eKISS is based on pictures and text, which gives the children communication media with good and wide expression possibilities. The use of pictures combined with text will function as a fairly rich expression media that will cover the wide range of needs from the different children. At the same time, most children are familiar with the use of pictures and text as an expression form, and we therefore hope they will find it easy and intuitive to use.

\section{EVALUATION}

We conducted an evaluation to explore the effects of eKISS and, in particular, to what extent eKISS supports intimacy between children and their parents. The evaluation was organized as a longitudinal field study. The aim of the study is to measure whether eKISS makes the parents gain additional insight in their children's lives while being apart, whether it makes it easier for the parent to communicate with and understand the children and if it aids the children in sharing their experiences.

Based on experiences from Counts and Fellheimer [2], which is a study performed to understand the intimate relations between children and parents, we decided to recruit new families. The decision was made because of a number of reasons. First, the three families that participated in the first study were all much alike. In this study, we wished to explore a more diverse group of families in order to explore possible differences in use due to different family structures. Second, the three families had all participated in a design process as part of the first study and we wished to avoid that these circumstances had any influence on the families' use of eKISS. Third, we were interested in evaluating the system with families that were separated for a number of days during the period of the study, because eKISS has been designed to mediate intimacy when family members are separated by distance.

\subsection{Participants}

Four families participated in the evaluation. All families lived and worked in the greater Aalborg area, Denmark. The families were recruited through mailing lists and contacts at Aalborg University, Denmark. We looked for families where parents would have access to the Internet and with children in the age of approximately 10-13 years old. The children should have access to a mobile phone during the day. In addition, we strived for rather different families to stress diversity in the use of eKISS. In this way, we settled at only four families, well aware that additional families could provide stronger results in terms of usage and motivation. We recruited families through a number of conversations and made sure that they were motivated and could participate in a longitudinal study over several weeks.

\subsubsection{Family One}

Family one was a one-parent family and consisted of a mother aged 40, a girl aged 11 and a boy aged 6 . The parents were divorced and the children lived with their mother. The father lived in the same town. The daughter went to school every day and four days a week she was at an after-school centre until three or half past three. She sang in a choir, played handball and took riding lessons. Each of these leisure activities were once every week. Every second weekend, and once during every week, she visited her father. She had a mobile phone which she used to call her mother if she needed to ask for permission to go somewhere after school or if she, for example, was late for an appointment with her mother.

The mother had access to the internet during work. She also had a mobile phone, which was sometimes used to send practical text messages to her daughter during the day or after work.

Every evening the family gathered for dinner. They often talked about what they had been doing during their day. It was mostly about the children's experiences. The mother wished that there was more time to talk to the children during the weekdays.

\subsubsection{Family Two}

Family two was a family of four, with a father aged 41 , a mother aged 39, a girl aged 12, and a boy aged 5. The parents worked full time and had access to the internet from work. The father was often separated from the rest of the family for several days due to business trips. When away he would talk to the rest of the family over the phone. He was a soccer coach for his son's team and trained two evenings every week. The father also had a home office where he often worked at night. The mother was active in the boards of directors in the girl's school and the boy's kindergarten. She was also attending courses as part of her job. All this combined took her away from the home around two nights a week. Sometimes she was also away from the family overnight because of her work.

The girl went to school every weekday. Three or four times a week, she attended leisure-time activities. She played the piano, played in an orchestra, took drama lessons and danced show dance. This meant that she was often away from home during an ordinary week. She had a mobile phone, which was mostly used for practical coordination with the rest of the family.

The family spent time with each other every morning and most evenings they were gathered for dinner. They tried to do things together on the weekends. The parents felt that their daughter was good at telling them about her experiences and how she was doing in school.

\subsubsection{Family Three}

Family three was a family of four with two parents. The mother was 38 and the father was 42 . The oldest boy was 11 years old and the youngest was six. Both parents worked full time. In the morning, they drove with each other to work. They both had mobile phones and had access to the internet from work.

The oldest son went to school every day. Sometimes he was in an after-school centre after school, but most afternoons he was with his friends or home alone with the family's dog. During the winter months, he played handball. He had his own mobile phone, which he used to call his parents when he left school. 
The family had dinner with each other almost every day and spent most evenings together. They were about to build a new house and therefore they were moving out of their current house. While they were building the new house, they were moving into an apartment in town. The parents did not feel that they needed to know more about the oldest boy's day in school, but they felt that it could be nice to know more about what he was doing when he was not in the classroom.

\subsubsection{Family Four}

Family four was a one-parent family with a mother aged 41, a boy and a girl. The boy was one year old and lived with his mother. The girl was 11 years old and lived with her father in a different part of the country. The mother worked full time and had access to the internet most of the day.

The girl went to school every day. In the afternoons, she was in an after-school centre. She was an athlete and one afternoon every week she was training or swimming depending on the time of year. On the weekends, she was with her father or her friends. She normally visited her mother and her younger brother approximately every second weekend, depending on her plans. She had her own mobile phone and talked with her mother on the phone several times every week. They talked about what they had been doing and about feelings if there was something they felt they needed to talk about. They also sent text messages, post cards and letters to each other.

The mother would like to know more about what her daughter was doing while she was with her friends or her father. Both parents were given access to eKISS, but only the mother and the daughter were interviewed for the study.

\subsection{Data Collection}

During the five-week period, we conducted contextual interviews with the families. When possible we arranged the interviews in the homes of the families to make them feel as comfortable as possible. Each of the interviews had the purpose of clarifying the families' communication and experiences with eKISS since the last interview. During every interview we produced a summary.

The first interview aimed to introduce the study and the functionalities in eKISS. The purpose this interview was to provide the families with an understanding of the work preceding the development of eKISS and to make sure that they knew what our purpose of the study was. The aim of the second interview was to make sure that the families were comfortable with eKISS and to answer their questions if anything had come up since our last interview. The aim of the interview was to follow up on and gain a deeper insight in the families' experiences with eKISS so far. Furthermore, we wished to present a number of changes for the last two weeks of the study. The aim of this interview was first to gain insight in the effects of the changes that was made at the last interview, if any. Second, we were interested in discussing the families' experiences with participating in the study and hearing about their ideas for further development of eKISS.

\section{FINDINGS}

The four families used eKISS in different ways and to different extents. These differences in use may be due to differences in the family structures, in the extent to which they are normally separated and in each of the children's desire to share experiences.
The children did not send as many pictures to eKISS as we had expected. During the entire period, they sent respectively 14 , 21,24 and 26 pictures. The family with most pictures were Family Four, who is normally separated by distance during periods of approximately two weeks. The family with 14 pictures lived together and saw each other on a daily basis. There have also been great differences in the number of visits to eKISS. The families have visited eKISS 29, 39, 64 and 134 times, respectively. The family with most visits was also the family who is normally separated by distance. From our data, it is not clear whether the separation is the greatest reason for the differences, but the parents' normal use of the internet and the availability of computers and internet access may also have contributed to these very different numbers. In the following, we present seven findings related to the families' use of eKISS.

\subsection{Initiation of Conversations}

The parents were able to see pictures of things or places they would not have seen without eKISS. This could be things that the children had made in school or places like the physics laboratory at the children's school. These pictures helped the parents to understand what the children experienced when they were away from home. Although the parents told us that they saw pictures of new things, they did not feel that the topics of their conversations changed during the period they were using eKISS. However, it became easier for the parents to initiate conversations about the children's experiences. They told us that they were able to avoid asking the 'stupid questions' and could ask about situations or objects, which they knew about from the pictures.

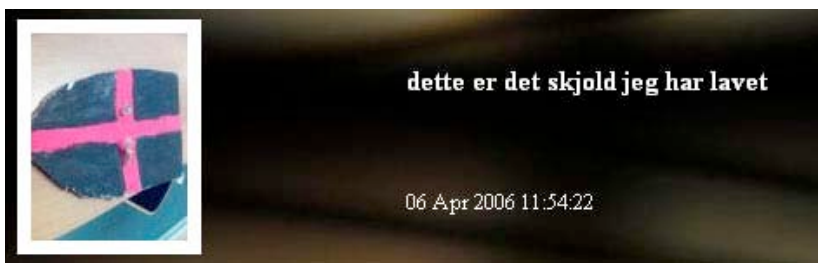

Figure 5. Example of a thing that the children could show their parents with help from eKISS. The note says"this is the shield I have made".

\subsection{Facilitating Interaction While Separated}

The parents have expressed different levels of needs to keep updated on their children's experiences via eKISS. Common for all parents were that they felt a greater desire for contact when they had been absent for a period of days, than when they saw their children every day. Some of the parents were away from the family for a number of days due to their work. At the interviews following these periods of separation they expressed that they had felt great satisfaction with eKISS while they were away because the pictures gave them a feeling of presence. They also felt that eKISS gave them something that a phone call could not have given them. They liked the fact that the pictures gave them an indication of the family's mood, which can be difficult to achieve through the phone. At the same time, they made it clear that the phone gave them a kind of connectedness that eKISS could not provide.

The type of pictures also changed while the parents were away. The family members that were with each other at home took pictures of situations in which they were doing things together. For example, one of the families took a picture of the first time they had a barbecue that year. That was something the father 
normally did with them, but due to his absence, he could only see the picture (see Figure 6 and 9 as examples).

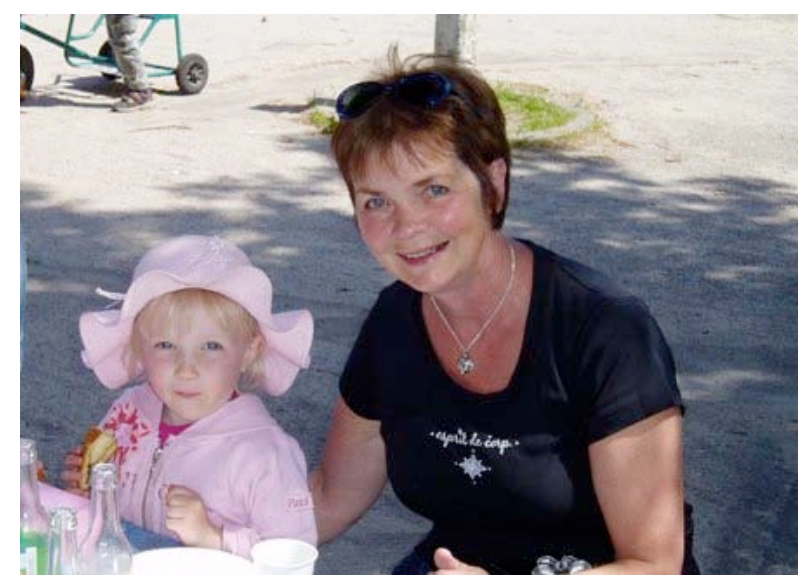

Figure 6. Example of a picture showing family members together. "It is nice here, [Name] was starving".

Our data do not indicate whether the children felt a greater need to share pictures with their parents while they were absent, only that the parents felt a greater desire to keep updated on the family's well-being while they were separated from them.

In most cases, the parents have only used the system while they were separated from their children. This was both at work during the day and at home in the evenings. We expected eKISS to be a part of the conversation that the children and parents had when they saw each other at the end of the day. One reason for the missing involvement of eKISS could be that they are often doing other things that prevent them from using a computer while talking. For example, most of the families talk about their day while eating dinner together. This situation makes it difficult to use eKISS since it requires a computer with internet access. Furthermore, the parents might not feel the need to see pictures of their children while they are with them.
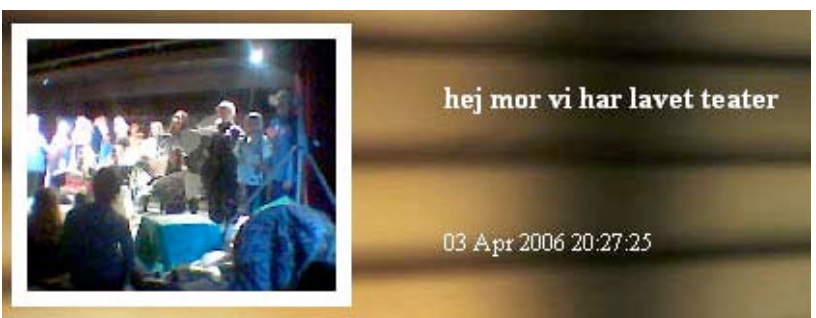

Figure 7. Example of picture intended for absent parent.

The note says, "Hi mom, we have been doing theatre".

During the five-week period, the schools were closed for a period of 11 days due to the Easter holidays. In this period, the families spent a lot of time together at home. In the days that the families were at home the use of eKISS almost stopped. The few pictures that were taken were mostly intended for parents that were separated from the rest of the family. This indicates that eKISS is most useful in situations where the families are apart, which was also the intended situations of use.

\subsection{Children Became Aware of Parents}

"I have thought more about what my mother might be doing when she sees the pictures I have taken". This was said by the daughter in Family Four, who was normally separated from her mother. The mother stated that she also felt that eKISS made her think more about what her daughter might be doing while she visited eKISS to see if she had shared new pictures. This gave us an indication that eKISS increased the level of awareness between the family members.

\subsection{Unclear and Unnecessary}

The children found it difficult to identify relevant and interesting motives. At our second interview, one of the children expressed "I want to take pictures. It's just hard to find things to photograph". The other children expressed the same problem. They did not feel that they could find anything that would be of interest for their parents. Because of this, most of the children forgot to take pictures. When they did take pictures, it was often "just the best thing I could find when I remembered to take a picture".

The lack of feedback in eKISS between the children and their parents could possibly explain some of these problems. The children received no immediate response from the parents or from any peer children on the pictures taken. Our findings indicate that the lack of information on responses to the pictures made it difficult for the children to assess when to take pictures and in what situations.

The lack of reflection also meant that when the children took pictures that the parents found useful it was mostly out of luck. The kind of pictures each of the four children took during the period has been very similar during the period although there have been variation in some of the pictures. The pictures mostly showed things the children had made in school or people that were with the person who took the picture.

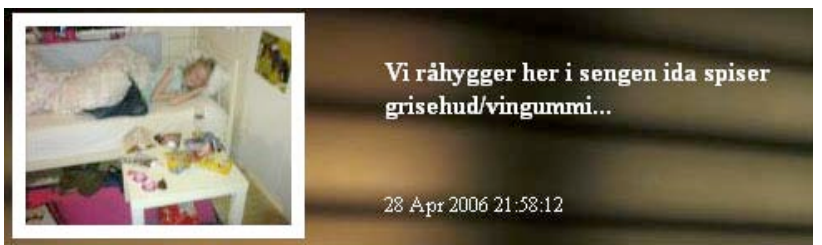

Figure 8. Picture showing a person who was with the child that took the picture. The note says, "We are having a cosy time in bed. Ida is eating pigskin/wine gum".

In an attempt to give the children ideas for new images and to help them remember to take the pictures, we made a number of changes as mentioned in the description of interview number three. They were given a note with ideas for images and we started prompting them via SMS-messages three times a day. At the same time, the grandparents were given access to eKISS. Some of the pictures that were taken after the changes had been introduced were different from what we had seen from the children earlier in the study. For instance, some of the children took pictures of themselves showing their mood (Figure 8).

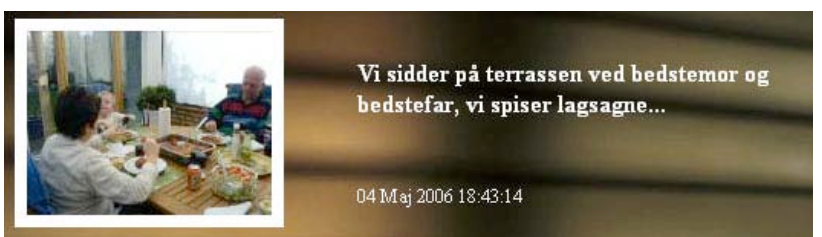

Figure 9. Example of a picture showing the other family members. The note says, "We are at the terrace at grandmother and grandfather, we are eating lasagna".

Another change was that the parents started appearing in a number of the pictures. One reason for this was that some of the pictures were no longer directed at the parents but instead at the grandparents. These pictures showed situations in which the 
whole family or part of the family was doing things together. In the interviews, the parents told us that they had encouraged the children to send the pictures in a number of these situations.

Most of the parents told us that the pictures they liked the most showed them something about their child's feelings or the mood they were in when the picture was taken. They felt that these pictures were confirmatory in situations where they were insecure of whether they were doing "the right thing". One of the families moved while we were doing the study. The day after they had moved the boy took a picture of himself smiling, and wrote a note that told his parents that he was with some of his friends. At the following interview one of the parents said, "We felt very happy to see that we were doing the right thing when moving closer to his friends".

Another example from the same family was that they had to give up their dog because they were moving. One day the boy had taken a picture of the dog and a football (see Figure 10). He had written a note saying that he had gone home to play football with the dog. This showed the parents that he was more upset about giving up the dog than they had known.

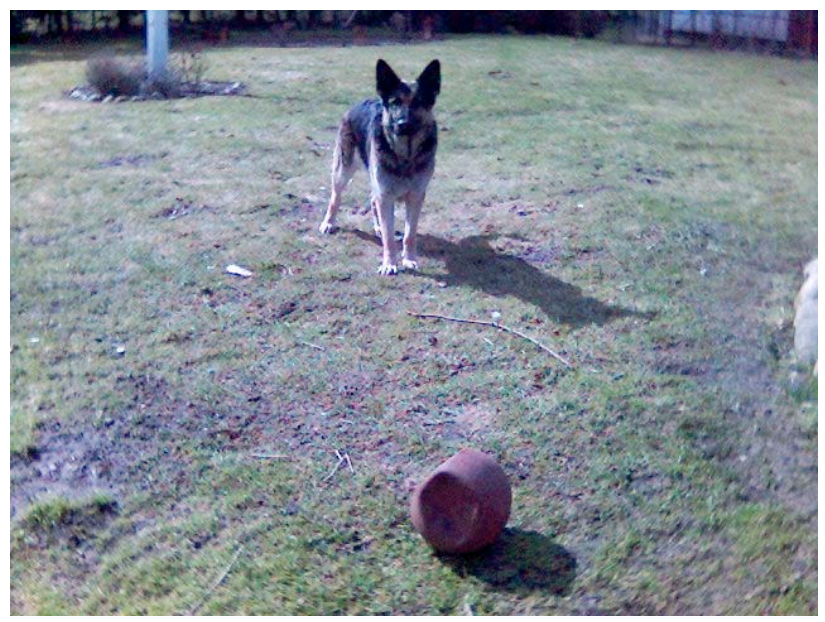

Figure 10. Example of picture that disclosed feelings.

In both these cases, the parents called each other at work and talked about the pictures, as soon as they had seen them. They waited to talk to their son until they were with him in the afternoon.

\subsection{Children Showed Minimal Interest in the Blog Pictures}

None of the children logged into the system to see their own pictures they have taken. We find this surprising, as we had expected that the children were curious to see how the pictures they had taken were presented in eKISS.

One reason for this could be a missing interest in eKISS and the study in general. The children did not volunteer for the project and were participating because their parents had found the study interesting. The children told us that they thought it was fun to take pictures with their mobile phones. Our data do not reveal if this was due to their politeness or because they actually liked taking pictures. However, we can see that none of the children has taken as many pictures as we had expected beforehand. A reason for the lack of enthusiasm from the children could be that the system only supports one-way communication. This could mean that the children find it hard to keep motivated when they are not receiving direct feedback. We had expected that eKISS could help increase the level of intimacy in the children's relationship with their parents and that the children thereby would be motivated to keep feeding the system with pictures. However, it seems that the added intimacy did not have that effect.

The quality of the pictures may also have been influenced by the fact that the children did not visit the weblog. They did not see for themselves how the pictures were presented and therefore they did not learn from the pictures they had taken earlier.

\subsection{Coordination and Note Writing}

Some children used eKISS for coordination purposes. As an example, a teacher had given one of the children a note that he should remember to show his parents. He took a picture of the note and published it in eKISS (illustrated in Figure 11). This way, the parents would know that the child should remember to give them the note. He also took pictures of his math book, when he should remember to do a number of exercises.

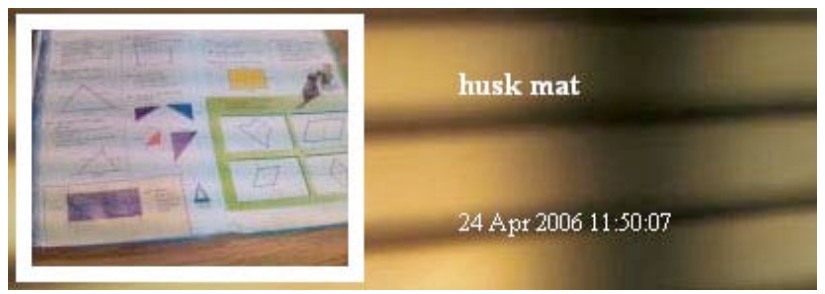

Figure 11. Picture showing schoolbook, with the note "remember math".

Although these pictures were mainly for their own use, the children did not see the pictures themselves, but relied on the parents to help them remember. We did not expect this kind of use before the study began.

\section{CONCLUSION}

In this paper, we presented eKISS a weblog for mediating intimacy between children and parents. eKISS was deployed and evaluated through a longitudinal study which indicated how eKISS contributed to the intimacy in four families.

The evaluations showed that eKISS provided new ways for the parents to gain insight in their children's lives while being apart. The parents used eKISS at work to be able to see what their children were doing. The parents' use of eKISS at home was limited, but the pictures made them able to initiate conversations about the children's day, using the pictures as reference. eKISS showed to be most useful when the family was separated for a longer period or when the child and parent lived apart. We found that eKISS made it possible for the parents to gain a better understanding of the experiences their children had. Through the pictures, they were able to see things, people and locations they normally did not see. This made it easier for them to understand the children when they described one of these things. We found that pictures with intimate or emotional contents were most useful for the parents. These pictures made it possible for them to discuss personal aspects with their children. For the children, we found that eKISS gave them an easy way of sharing things with their parents. It also enhanced their feeling of presence towards the parents, as the task of taking pictures, made them think of the parents. Even though the children had positive effects from using eKISS, they were not motivated to take the pictures. They found it difficult to find motives and difficult to remember to take the pictures.

Our study is limited in a number of ways. First and perhaps foremost, the lack of feedback or reciprocity caused the 
children to adapt the system less than we aimed at. The lack of feedback seemed to prohibit a learning process where the parents could offer their immediate perspectives and impressions of the shared pictures. The anticipated learning during dinnertime or similar was less obvious than we initially expected. Second, families are very different and have diverse objectives, traditions, and norms. Our study only involved four families over a five-week period. Thus, it is difficult to generalize all results from our deployment of eKISS as other families might have used it quite differently. In addition, the participating families faced different situations where the need for using eKISS varied a great deal. Not surprisingly, physical separation proved to be a crucial factor in the motivation for using eKISS actively.

Our study identifies several avenues for further research within mediated intimacy in families. First, how can we design systems that allow more seamlessly synchronous communication and interaction? SMS or text-messages allow children and parents to communicate during separation but our first study indicated that children are less willing to engage in such conversation or communication with their parents. Additional studies could look into new ways of supporting conversations in order to mediate intimacy. Second, how can we design systems that more easily support communication of moods between children and parents? Initially we hoped that the sharing of pictures would reveal much more of the wellbeing and mood of the children. However, this was not the case. We need further studies that investigate into communicating moods of children to their parents so that the parents could take action in specific situations.

\section{ACKNOWLEDGMENTS}

The work behind this paper has received financial support from the Danish Research Agency (grant no. 2106-04-0022). We would especially like to thank all the participating families. In addition, we would like to thank several anonymous reviewers for comments on earlier drafts of the paper.

\section{REFERENCES}

[1] Battarbee, K., Baerten, N., Hinfelaar, M., Irvine, P., Loeber, S., Munro, A., and Pederson, T. Pools and satellites: Intimacy in the city. In Proceedings of the conference on Designing interactive systems: Processes, practices, methods, and techniques (DIS 2002). ACM Press, New York, NY, 2002, 237-245.

[2] Counts, S., and Fellheimer, E. Supporting social presence through lightweight photo sharing on and off the desktop. In Proceedings of the SIGCHI conference on Human factors in computing systems (CHI 2004). ACM Press, New York, NY, 2004, 599-606.

[3] Dalsgaard, T., Stougaard, M., and Thomassen, B. R. Classifying Mediated Intimacy Research: Understanding the Influence of Intimacy Relations. Department of Computer Science, Aalborg University, Denmark, 2006.

[4] Dalsgaard, T., Skov, M. B., Stougaard, M., and Thomassen, B. Mediated intimacy in families: Understanding the relation between children and parents. In Proceedings of the 5th international conference on interaction design and children (IDC 2006). ACM Press, New York, NY, 2006, 145-152.

[5] Hansen, G. L. Effective Family Communication: We Just Don't Communicate. University of Kentucky Cooperative Extension Service, 1997. http://www.uky.edu/Ag/Sociology/effamcom.htm
[6] Hoefnagels, S., Geelhoed, E., Stappers, P. J., Hoeben, A., and van der Lugt, R. Friction in scheduling and coordinating lives of families: Designing from an interaction metaphor. In Proceedings of the conference on Designing interactive systems: Processes, practices, methods, and techniques (DIS 2004). ACM Press, New York, NY, 2004, 321-324.

[7] Hindus, D., Mainwaring, S.D., Leduc, N., Hagström, A. E., and Bayley, O. Casablanca: Designing social communication devices for the home. In Proceedings of the SIGCHI conference on Human factors in computing systems (CHI 2001). ACM Press, New York, NY, 2001, 325-332.

[8] Jacobsen, M. H., Tonboe, J., and Reitzel, H. Arbejdssamfundet: Den Beslaglagte Tid og Den Splittede Identitet. Hans Reitzels Forlag (2004), 87-412-2329-2

[9] Kjeldskov, J., Gibbs, M. R., Vetere, F., Howard, S., Pedell, S., Mecoles, K., and Bunyan, M. Using cultural probes to explore mediated intimacy. In Proceedings of $\mathrm{OzCHI}$ 2004. (University of Wollongong, November, 2004). 2004.

[10] Markopoulos, P., Romero, N., van Baren, J., de Ruyter, B., and Farshchian, B. Keeping in touch with the family: Home and away with the ASTRA awareness system. In Proceedings of the SIGCHI conference on Human factors in computing systems (CHI 2004). ACM Press, New York, NY, 2004, 1351-1354.

[11] Stevens, M. M., Abowd, G. D., Truong, K. N., and Vollmer, F. Getting into the Living Memory Box: Family archives and holistic design. Personal and Ubiquitous Computing, 7, 3 (2003), 210-216.

[12] O'Hara, K., Harper, R., Unger, A., Wilkes, J., Sharpe, B., and Jansen, M. TxtBoard: From text-to-person to text-tohome. In CHI 2005: Extended abstracts of the SIGCHI conference on Human factors in computing systems. ACM Press, New York, NY, 2005, 1705-1708.

[13] Plaisant, C., Druin, A., and Hutchinson, H. Technologies for families. In CHI 2002: Extended abstracts of the SIGCHI conference on Human factors in computing systems. ACM Press, New York, NY, 2002, 938-939.

[14] Siio, I., Rowan, J., and Mynatt, E. Peek-a-drawer: Communication by furniture. In CHI 2002: Extended abstracts of the SIGCHI conference on Human factors in computing systems. ACM Press, New York, NY, 2002, 582-583.

[15] Sloane, H. Parenting: What Can A Parent Do. Cambridge Center for Behavioral Studies.

http://www.behavior.org/parenting/index.cfm?page=http\% $3 \mathrm{~A} / /$ www.behavior.org/parenting/parenting_commentary_ sloane.cfm

[16] Vetere, F., Gibbs, M. R., Kjeldskov, J., Howard, S., Mueller, F., Pedell, S., Mecoles, K., and Bunyan, M. Mediating intimacy: Designing technologies to support strong-tie relationships. In Proceedings of the SIGCHI conference on Human factors in computing systems (CHI 2005). ACM Press, New York, NY, 2005, 471-480.

[17] XSL Transformations (XSLT) Version 1.0. W3C Recommendation 16 November 1999. http://www.w3.org/TR/xs

[18] Zuckerman, O., and Maes, P. Awareness system for children in distributed families. In Proceedings of the 4th international conference on Interaction design and children (IDC 2005). ACM Press, New York, NY, 2005. 
